\title{
The effect of water and isotonic saline preloads on the reduction of complex thirst
}

\author{
RICHARD A. WYRICK \\ University of North Carolina School of Medicine, Chapel Hill, North Carolina 27514
}

\begin{abstract}
This study investigated the effects of preloads of drinking following the induction of hypercomplex thirst in 28 female Wistar rats. Food and water were removed for $24 \mathrm{~h}$. PG (5 ml) and hypotonic saline $(3 \mathrm{ml}$ ) were injected 6 and $1 \mathrm{~h}$, respectively, before water was presented for $1 \mathrm{~h}$. One-half hour before drinking, four preload treatments were administered: (a) $5 \mathrm{ml}$ tap water, (b) $5 \mathrm{ml}$ isotonic saline, (c) $5 \mathrm{ml}$ water and $5 \mathrm{ml}$ isotonic saline, or (d) sham intraperitoneal injection. Through successive trials, each rat received each treatment. Water preloads and isotonic saline preloads significantly reduced drinking. Water and water plus isotonic saline reduced drinking significantly more than isotonic saline. Under the present conditions, cellular dehydration was a much more dominant stimulus than hypovolemia. Contrary to expectation, water plus isotonic saline preloads did not reduce drinking more than water preloads alone. Apparently the additivity of complex thirst stimuli previously shown during induction does not extend to preload reduction.
\end{abstract}

The present study was concerned with the effects of water, isotonic saline, and combined water and isotonic saline preloads on drinking following the hypercomplex stimulus of water deprivation, hypovolemia, and cellular dehydration. Since hypertonic saline and hyperoncotic colloidal solutions are additive in inducing complex thirst (Corbit, 1968) and have been shown to add their effects to those of water deprivation (Fitzsimons \& Oatley, 1968), it was expected that water, which more effectively reduces osmotic thirst, and isotonic saline, which more effectively reduces hypovolemic thirst (Stricker \& Wolf, 1967), would add to inhibit drinking. Given that the present stimulus conditions involved water deprivation and pretrial hypertonic saline injections, it was predicted that water preloads would be more effective than isotonic saline but less effective than water and isotonic saline combined.

\section{METHOD}

Twenty-eight female Wistar rats were individually housed in a constantly illuminated laboratory at a temperature of $70^{\circ} \mathrm{F}$ and humidity of $44 \%-47 \%$. A 100 -ml graduated tube with metal tip was mounted on each home cage to measure water intake. A 250-ml glass beaker was fastened at the corner of each cage for feeding. Powdered Purina Lab Chow was used. Food intake was not measured. Water intake was read to the nearest $1 \mathrm{ml}$.

Subjects were run in two squads of 14 each, approximately 12 days apart. All procedures were held constant for both squads. Rats were adapted to a schedule of 1-day total deprivation and 1-day feeding-drinking for 8 days. On feeding-drinking days, water alone was presented for $1 \mathrm{~h}$, followed by food and water

This study was conducted at the University of Arizona. Dr. Sigmund Hsiao is acknowledged for his assistance in the design and interpretation of this experiment. Requests for reprints should be sent to Richard Wyrick, Department of Psychiatry, University of North Carolina Medical School, Chapel Hill, North Carolina 27514. for $23 \mathrm{~h}$. By the 8th day of the adaptation period, water intake was stable, rats quickly approached and drank from the presented tube, and the experiment was begun.

To induce thirst, food and water were removed for $24 \mathrm{~h}$. Six hours before water presentation, each rat was lightly etherized and given a backskin-behind-the-neck subcutaneous injection of a hyperoncotic colloid $-5 \mathrm{ml}$ of $10 \%(\mathrm{w} / \mathrm{v})$ polyethylene glycol (molecular weight $=20,000$ ) dissolved in isotonic saline. One hour before presentation of water, each subject was given an intraperitoneal injection of $3 \mathrm{ml}$ of $1 \mathrm{M} \mathrm{NaCl}$ solution.

In order to examine the inhibiting effects of preloads on drinking, rats were divided into four groups. Thirty minutes before water presentation, each group received one of the following: (a) intraperitoneal injection of $5 \mathrm{ml}$ of tap water, (b) $5 \mathrm{ml}$ of $.9 \% \mathrm{NaCl}(\mathrm{w} / \mathrm{v})$ solution, (c) $5 \mathrm{ml}$ of tap water and $5 \mathrm{ml}$ of $.9 \% \mathrm{NaCl}(\mathrm{w} / \mathrm{v})$ solution, or (d) sham injection with needle puncture only. Thirty minutes after the injection, water was presented for $1 \mathrm{~h}$ and intake was measured. Before receiving the next condition, rats were given free access to food and water for a 2-day recovery period. To equate for possible carryover effects, all four groups were given all four conditions in a Latin square design so that every condition was preceded by all other conditions.

\section{RESULTS}

Table 1 presents the mean water intakes for the four conditions. An analysis of variance of water intake as a function of preload treatments showed a significant reduction of drinking with water preloading and isotonic saline preloading. No significant interaction between treatments was found. Replication effects were nonsignificant, justifying the merger of the squads and consideration of total sample means. When each treatment was compared with the sham control condition, water preloads, $\mathrm{t}(27)=5.65$, $\mathrm{p}<.005$, isotonic saline preloads, $\mathrm{t}(27)=3.09$, $\mathrm{p}<.005$, and water-plus-isotonic-saline preloads, $\mathrm{t}(27)=5.71, \mathrm{p}<.005$, all significantly reduced drinking. Other comparisons indicated that water preloads were significantly more effective than saline 
Table 1

Mean 1-H Water Intake (Milliliters) as a Function of Preload Treatments

\begin{tabular}{lccc}
\hline \multicolumn{1}{c}{ Preload } & $\begin{array}{c}\text { Total Sample } \\
(\mathrm{n}=28)\end{array}$ & $\begin{array}{c}\text { Squad 1 } \\
(\mathrm{n}=14)\end{array}$ & $\begin{array}{c}\text { Squad 2 } \\
(\mathrm{n}=14)\end{array}$ \\
\hline Water & 12.57 & 13.36 & 11.79 \\
Isotonic saline & 14.61 & 14.93 & 14.28 \\
Water plus isotonic saline & 12.32 & 13.36 & 11.29 \\
Sham & 16.39 & 17.43 & 15.36 \\
\hline
\end{tabular}

Table 2

Analysis of Variance of Water Intake as a Function of Preloads

\begin{tabular}{|c|c|c|c|}
\hline Source & $\mathrm{df}$ & MS & $\mathrm{F}$ \\
\hline $\begin{array}{l}\text { Between Subjects } \\
\text { Replication (A) } \\
\text { Error between }\end{array}$ & $\begin{array}{r}27 \\
1 \\
26\end{array}$ & $\begin{array}{l}70.72 \\
30.32\end{array}$ & 2.33 \\
\hline $\begin{array}{l}\text { Within Subjects } \\
\text { Water (B) } \\
\text { A by B } \\
\text { B by Subject with replications } \\
\text { Isotonic Saline (C) } \\
\text { A by C } \\
\text { C by Subject with replications } \\
\text { Water by Isotonic Saline (B by C) } \\
\text { A by B by C } \\
\text { B by C by Subject with } \\
\text { replications }\end{array}$ & $\begin{array}{r}84 \\
1 \\
1 \\
26 \\
1 \\
1 \\
26 \\
1 \\
1\end{array}$ & $\begin{array}{r}9.33 \\
260.24 \\
2.35 \\
5.68 \\
29.01 \\
1.51 \\
5.87 \\
17.35 \\
5.67 \\
\\
6.43\end{array}$ & $\begin{array}{c}45.82^{* *} \\
.41 \\
4.94^{*} \\
.26 \\
\\
2.70 \\
.88\end{array}$ \\
\hline
\end{tabular}

preloads in reducing drinking, $\mathrm{t}(27)=3.52, \mathrm{p}<.005$, and water-plus-isotonic-saline preloads were significantly more effective than saline preloads in reducing drinking, $\mathrm{t}(27)=3.16, \mathrm{p}<.005$. Mean water intake did not significantly differ for the water and waterplus-isotonic-saline preload treatments, $\mathrm{t}(27)=.41$, $\mathrm{p}>.10$.

\section{DISCUSSION}

Water preloads and isotonic saline preloads significantly reduced drinking following the hypercomplex thirst stimulus of water deprivation, hypovolemia, and cellular dehydration. Solutions of water and water plus isotonic saline reduced drinking significantly more than solutions of isotonic saline alone. Clearly, under the present experimental conditions, cellular dehydration was a much more dominant stimulus than hypovolemia.

Since a nonsignificant interaction was shown between significant main treatments, the results might be interpreted to suggest, as predicted, that the reduction of drinking was additive. However, to conclusively test the additivity hypothesis, it was also expected that water-plus-isotonic-saline preloads would reduce drinking significantly more than water preloads alone. This prediction was not confirmed. Apparently, either water and isotonic saline did not function in an additive manner to reduce drinking or the actual contribution of isotonic saline was very slight. Inspection of water intake levels suggests that the reduction of hypercomplex thirst was not additive. The present findings are somewhat inconsistent with the apparent activity of osmotic and hypovolemic stimuli found during the induction of complex thirst (Corbit, 1968; Fitzsimons \& Oatley, 1968).

\section{REFERENCES}

Corbit, J. D. Cellular dehydration and hypovolemia are additive in producing thirst. Nature, 1968, 218, 886-887.

Fitzsimons, J. T., \& OATLEY, K. Additivity of stimuli for drinking in rats. Journal of Comparative and Physiological Psychology, 1968, 66, 450-455.

STRICKER, E. M., \& Wolf, G. Hypovolemic thirst in comparison with thirst induced by hyperosmolarity. Physiology and Behavior, 1967, 2, 33-37.

(Received by Publications Office April 26, 1976.) 